\title{
Differential Excitation of Distally versus Proximally Targeting Cortical Interneurons by Unitary Thalamocortical Bursts
}

\author{
낙ang Hu and Ariel Agmon \\ Department of Neurobiology and Anatomy and the Sensory Neuroscience Research Center, West Virginia University School of Medicine, Morgantown, \\ West Virginia 26506
}

\begin{abstract}
Thalamocortical neurons relay sensory and motor information to the neocortex using both single spikes and bursts; bursts prevail during low-vigilance states but also occur during awake behavior. Bursts are suggested to provide an alerting signal to the cortex and enhance stimulus detection, but the synaptic mechanisms underlying these effects are not clear, because the postsynaptic responses of different subtypes of cortical neurons to unitary thalamocortical bursts are mostly unknown. Using optogenetically guided recordings in mouse thalamocortical slices, we achieved the first reported paired intracellular recordings from nine monosynaptically connected thalamic and cortical neurons, including principal cells and two subtypes of inhibitory interneurons, and compared between cortical responses to single thalamocortical spikes and bursts. In 18 additional cortical neurons, we elicited unitary burst responses optogenetically. Shortterm dynamics and temporal summation of burst-evoked EPSPs were cell-type dependent: in principal cells and somatostatin-containing (SOM), but not fast-spiking (FS), interneurons, peak response during a burst was on average more than twofold larger than the response to the first spike. Thus, firing a burst instead of a single spike would more than double the probability of firing in postsynaptic excitatory neurons and in SOM, but not FS, interneurons. Consistent with this prediction, FS interneurons held near firing threshold fired most often on the first burst component, whereas SOM interneurons fired only on the second or later components. By increasing excitation of principal cells together with SOM-mediated, distally directed inhibition, thalamocortical bursts could momentarily enhance the saliency of the ascending sensory stimulus over less urgent, top-down inputs.
\end{abstract}

Key words: barrel cortex; fast-spiking; low-threshold bursts; somatostatin; thalamocortical; unitary EPSPs

\section{Significance Statement}

Thalamocortical neurons relay sensory and motor information to the cerebral cortex using both single spikes and high-frequency bursts, but the function of bursts is not fully understood. Using brain slices from mouse somatosensory thalamus and cortex, we achieved the first dual recordings of directly connected thalamic and cortical neurons and compared between cortical responses to single thalamic spikes and to bursts. We report that bursts enhanced the responses of excitatory neurons and of inhibitory interneurons that preferentially target dendrites. A potential consequence is that bursts will enhance the response to the immediate sensory event over responses to less urgent, modulatory inputs.

\section{Introduction}

Nearly all sensory and motor information reaches the neocortex through an obligatory relay in the thalamus, making the thalamo-

\footnotetext{
Received March 6, 2016; revised April 24, 2016; accepted May 16, 2016.

Author contributions: A.A. designed research; H.H. performed research; H.H. and A.A. analyzed data; A.A. wrote the paper.

This work was supported by Grant NS050437 from the National Institutes of Health (A.A.). We thank Drs. Yael Amitai, Erika Fanselow, Gary Marsat, Liset Menendez de la Prida, George Spirou, Karel Svoboda, Eric Tucker, and Jianing Yu for valuable suggestions on this and previous versions of this manuscript and Qingyan Wang for excellent technical assistance. The SERT-Cre mice used in initial experiments were generously provided by Dr. Venkatesh Murthy.

The authors declare no competing financial interests.

Correspondence should be addressed to Ariel Agmon, Department of Neurobiology and Anatomy and the Sensory Neuroscience Research Center, P.O. Box 9303, West Virginia University School of Medicine, Morgantown, WV 26506. E-mail: aric.agmon@gmail.com.
}

cortical synapse a crucial linchpin of brain function in health and disease. Thalamocortical relay neurons communicate with their cortical targets using either single spikes or high-frequency bursts riding on a Ca-mediated low-threshold spike (LTS), depending on their membrane potential (Jahnsen and Llinás, 1984; Zhan et al., 1999). Bursts are most common during sleep, anesthesia, and low-vigilance awake states, during which thalamocortical neurons are relatively hyperpolarized (Domich et al., 1986; Steriade et al., 1993; Bezdudnaya et al., 2006). Importantly, however, bursts also occur during awake behavior (Guido and Weyand, 1995; Ramcharan et al., 2000; Fanselow et al., 2001; Weyand et al., 
2001). As in other sensory systems (Krahe and Gabbiani, 2004), thalamocortical bursts likely play an important role in encoding sensory information. For example, during visual processing of natural scenes, $\sim 25 \%$ of all spikes in the visual thalamus occur in bursts (Lesica and Stanley, 2004), and encoding of sensory information by bursts is estimated to be threefold more efficient than by single spikes (Reinagel et al., 1999). Thalamic bursts have also been proposed to code the saliency of a stimulus (MartinezConde et al., 2002) and to act as an alerting "wakeup" signal to the cortex (Sherman, 2001), enhancing stimulus detection at the expense of response linearity (Lu et al., 1992; Guido et al., 1995).

Why would thalamocortical bursts affect the cortical network differently than single spikes? Thalamocortical bursts tend to occur after a period of relative quiescence, which allows the underlying Ca conductance to recover from inactivation (Coulter et al., 1989; Wang et al., 1991; Lu et al., 1992). The same prolonged quiescence also allows thalamocortical synapses to recover from chronic short-term depression (Castro-Alamancos and Oldford, 2002; Chung et al., 2002; Swadlow et al., 2002). The combined result is that the first spike in the burst will activate a relatively undepressed synapse and elicit a considerably larger excitatory response compared with the average single spike (Swadlow and Gusev, 2001). Bursts could also enhance the postsynaptic response through temporal summation, when successively arriving EPSPs accumulate faster than they can dissipate (Kim and McCormick, 1998; Usrey et al., 2000). Conversely, high-frequency firing causes strong short-term depression of many thalamocortical synapses (Galarreta and Hestrin, 1998; Beierlein and Connors, 2002; González-Burgos et al., 2004; Gabernet et al., 2005; Kloc and Maffei, 2014), counteracting temporal summation. Moreover, thalamocortical inputs excite inhibitory cortical interneurons more strongly than they excite principal cells (Porter et al., 2001; Bruno and Simons, 2002; Gabernet et al., 2005; Sun et al., 2006; Cruikshank et al., 2007), so even if thalamocortical transmission is enhanced by a burst, it is not a priori clear whether the net effect on the cortical network would be excitatory or inhibitory. This is especially acute given the diversity of inhibitory cortical neurons and their potential to be affected differentially by thalamocortical spike trains (Tan et al., 2008; Takesian et al., 2013). Given these multiple contributing factors and their cell-type dependency, the best approach for studying the effects of thalamocortical bursts is paired intracellular recordings from identified, monosynaptically connected thalamic and cortical neurons, but this is a technically challenging experiment that has not been reported previously. Using optogenetically guided recordings in thalamocortical slices, we achieved the first reported recordings from monosynaptically connected thalamic and cortical neurons, the latter including excitatory cells and two different inhibitory interneuron subtypes. We compared responses of postsynaptic cortical cells to single thalamocortical spikes with responses to LTS-mediated bursts and confirmed these results in a separate dataset of cortical neurons in which thalamocortical burst responses were elicited optogenetically. We found that, relative to their first spike, thalamocortical bursts preferentially enhanced the response of principal cells and distally targeting, but not proximally targeting, inhibitory interneurons, potentially suppressing top-down inputs and increasing the saliency of the ascending stimulus.

\section{Materials and Methods}

Animals. Experiments were approved by the West Virginia University Animal Care and Use Committee and followed all U.S. Public Health Service policies and guidelines for responsible and humane animal ex- perimentation. Mice used for experiments were a cross between the GENSAT KN282 transgenic line (MMRRC strain 036680-UCD; Gerfen et al., 2013) and the channelrhodopsin (ChR2) Cre-responder line Ai32 (stock \#024109, The Jackson Laboratory; Madisen et al., 2012). The KN282 line exhibits strong Cre recombinase expression in the ventrobasal (VB) thalamus, with negligible expression in other thalamic nuclei or barrel cortex neurons (http://www.gensat.org/cre.jsp). For targeting somatostatin-containing (SOM) interneurons, the X94 line (stock \#006344, The Jackson Laboratory; Ma et al., 2006) was bred into the mix, generating triple transgenic animals in which thalamic neurons expressed ChR2 and enhanced yellow fluorescent protein and a subset of layers 4/5 SOM interneurons expressed GFP. In initial experiments, we used the SERT-Cre line (Zhuang et al., 2005) instead of the KN282 line to express ChR2 in the thalamus; one pair was recorded in this line. We discontinued using this line because of its substantial Cre expression in cortical neurons.

Slice preparation. Juvenile mice (14- to 23-d-old) of either sex were deeply anesthetized with isoflurane (Abbott Laboratories) and decapitated, and the brains were removed and submerged in ice-cold cutting solution consisting of the following (in $\mathrm{mM}$ ): 206 sucrose, 11 glucose, 1.25 $\mathrm{NaH}_{2} \mathrm{PO}_{4}, 26 \mathrm{NaHCO}_{3}, 0.5 \mathrm{CaCl}_{2}, 10 \mathrm{MgCl}_{2}$, and $2.5 \mathrm{KCl}$, pH 7.4. Using a Vibroslicer (World Precision Instruments), $450-\mu \mathrm{m}$-thick thalamocortical slices (Agmon and Connors, 1991; Porter et al., 2001) were cut in the same solution and then transferred into a holding chamber filled with recirculated artificial CSF (ACSF; in mM: $126 \mathrm{NaCl}, 3 \mathrm{KCl}, 1.25$ $\mathrm{NaH}_{2} \mathrm{PO}_{4}, 2 \mathrm{CaCl}_{2}, 1.3 \mathrm{MgSO}_{4}, 26 \mathrm{NaHCO}_{3}$, and 20 D-glucose). All solutions were saturated with $95 \% / 5 \% \mathrm{O}_{2} / \mathrm{CO}_{2}$. Cut slices were incubated at $32^{\circ} \mathrm{C}$ for at least $30 \mathrm{~min}$ and then kept at room temperature until used. For recording, slices were transferred to a submersion recording chamber and continuously superfused at a rate of $2-3 \mathrm{ml} / \mathrm{min}$ with ACSF at $32^{\circ} \mathrm{C}$. Glass micropipettes (typically $5-8 \mathrm{M} \Omega$ in resistance) were filled with the following: $134 \mathrm{~mm}$ K-gluconate, $3.5 \mathrm{~mm} \mathrm{KCl}, 0.1 \mathrm{mM} \mathrm{CaCl}_{2}, 10$ mM HEPES, 1.1 mм EGTA, 4 mм Mg-ATP, 10 mм phosphocreatine-Tris, and $2 \mathrm{mg} / \mathrm{ml}$ biocytin, adjusted to $\mathrm{pH} 7.25$ and $290 \mathrm{mOsm}$.

Paired thalamus-cortex recordings. A whole-cell recording configuration was established on a cortical neuron in layer $5 \mathrm{~b}$ or 4 of the barrel cortex, and the neuron was characterized by a standard protocol of subthreshold and suprathreshold current steps. The VB nucleus in the thalamus was then scanned manually under a $40 \times$ objective while applying 50-100 ms pulses of blue light using a collimated epi-illumination light source (Lumen 200; Prior Scientific), until a postsynaptic response was observed in the cortical cell. The light intensity and duration were then gradually reduced to eliminate polysynaptic activation, simultaneously stopping down the field diaphragm to narrow the illuminated area and identify the topologically aligned region in the thalamus. Once a small region in the thalamus has been identified from which brief light pulses elicited postsynaptic responses at short and constant latencies, neurons in that region were patched one by one until a connection was found or until the cortical recording was lost. When a dual recording was established, the synaptic connection was characterized by eliciting single thalamocortical spikes (by a depolarizing step from a holding potential of $-50 \mathrm{mV}$ ) or bursts (by a depolarizing step from the resting potential of approximately $-60 \mathrm{mV}$ or by terminating a hyperpolarizing step) at 0.2 $\mathrm{Hz}$, while holding the cortical neuron at its resting potential and monitoring its response. Typically, 20-40 responses to single spikes and 5-25 responses to bursts of equal spike numbers were averaged, after aligning the responses on the (first) presynaptic spike.

Data analysis and statistics. Intrinsic physiological parameters were defined and measured as done previously (Ma et al., 2006). Measurements of synaptic parameters were done on the averaged responses, except for latency, which was measured on a trial-by-trial basis to determine the coefficient of variation $(\mathrm{CV})$. Latency was measured from peak presynaptic spike to EPSP onset (Fig. $1 G$, arrows). For single-spike responses, amplitude was measured from baseline (immediately before EPSP onset) to peak, rise time was measured from 10-90\% of amplitude, and decay was fitted with a single exponential. For burst responses, individual component EPSPs of the same order (e.g., all second EPSPs, all third EPSPs, etc.) were first aligned on their onset and then averaged, to compensate for presynaptic spike jitter. The amplitude of each compo- 
RS

A

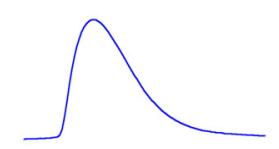

D
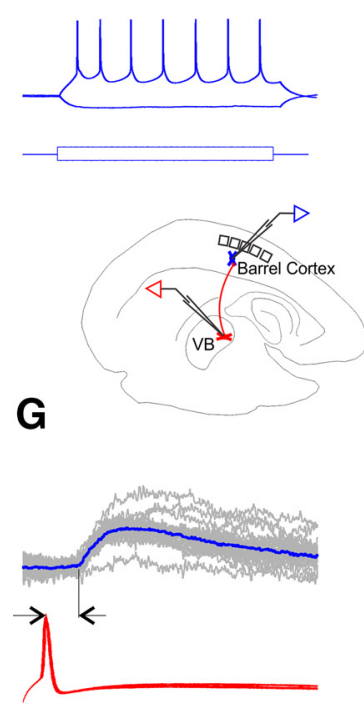

J

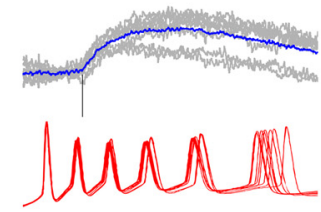

M

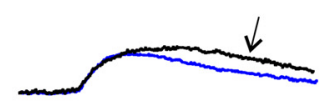

P

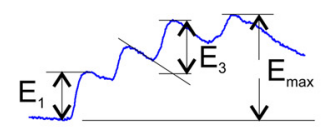

FS
B

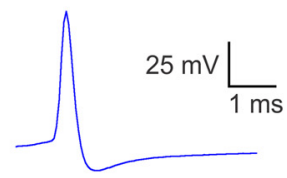

E

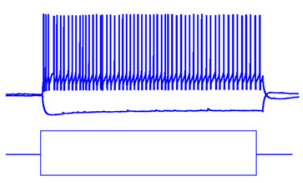

$50 \mathrm{mV}$ $800 \mathrm{pA}$

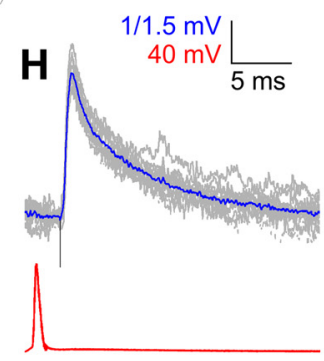

K

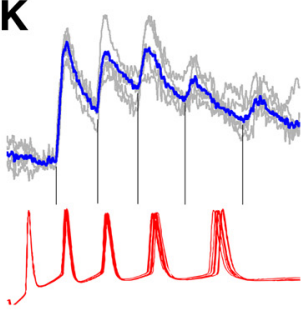

N

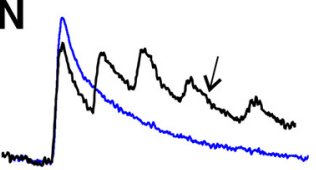

Q

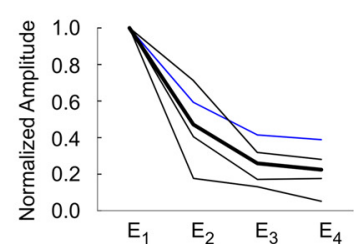

F

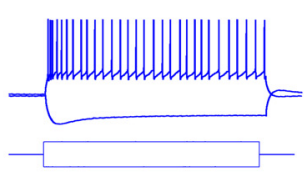

$100 \mathrm{~ms}$

C
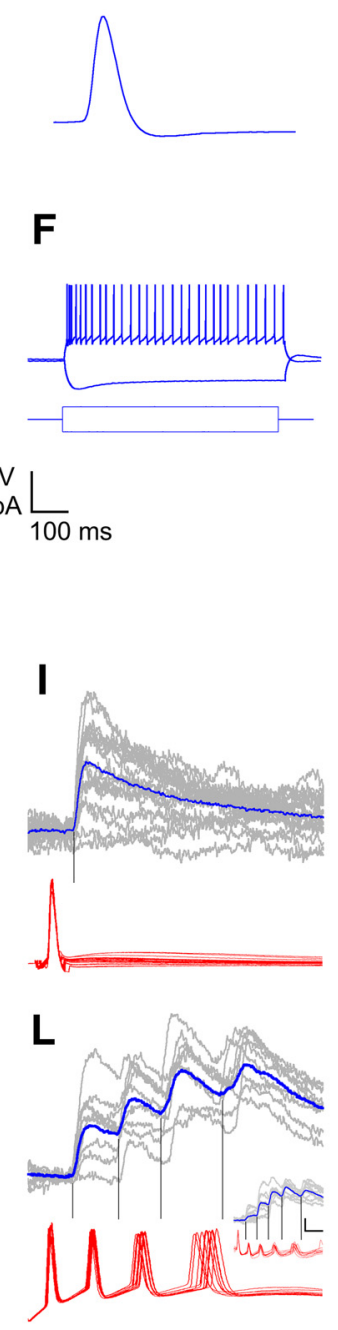

0

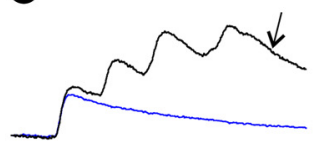

R

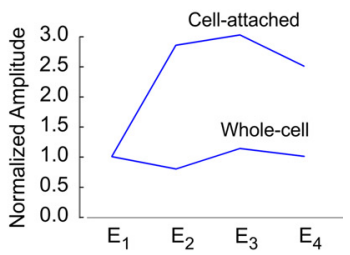

Figure 1. Single-spike and burst-induced unitary thalamocortical EPSPs in three cortical cell types. $A-C$, Spike waveforms of three example cells; note the characteristic differences in spike widths. $\boldsymbol{D}-\boldsymbol{F}$, Voltage responses (top traces) to intracellular current steps (bottom traces); note the pronounced spike rate adaptation of the SOM compared with the FS cell. Diagram below $\boldsymbol{D}$ illustrates the dual recording configuration. G-I, Unitary thalamocortical EPSPs (superimposed single sweeps in gray, averages in blue) elicited by single thalamocortical spikes (superimposed red traces). Vertical guidelines indicate EPSP onset; the horizontal arrow in $\mathbf{G}$ illustrates how latencies were measured. $\boldsymbol{J}-\boldsymbol{L}$, Unitary bEPSPs (superimposed single sweeps in gray, averages in blue) elicited by unitary thalamocortical bursts (superimposed red traces). Vertical guidelines indicate onset of individual bEPSP components, when discernible. The inset in $\boldsymbol{L}$ shows the response when the presynaptic neuron was in the cell-attached mode, before break-in. Calibration (in inset): $1.5 \mathrm{mV}$ (top traces) and $4 \mathrm{mV}$ (bottom traces), $5 \mathrm{~ms}$. $\mathbf{M} \mathbf{- 0}$, The averaged single-spike (blue) and burst (black) EPSPs in each cell, superimposed for comparison; burst responses indicated by arrows. $\boldsymbol{P}$, Illustration of the nent was then measured on the averaged trace, from a baseline determined by the intersection of a vertical line passing through the peak and a straight line fit by eye to the last $3 \mathrm{~ms}$ before EPSP onset (Fig. 1P). The overall amplitude of the burst response $\left(E_{\max }\right)$ was measured on the averaged trace without compensating for jitter and is therefore an underestimate. Statistical significance was computed using MathCad (PTC), by performing 10,000 random permutations of the data and calculating the fraction of permutations resulting in equal or more extreme values of the relevant statistic. Data are reported as mean \pm SEM unless indicated otherwise.

Neurolucida reconstructions. Slices were processed for DAB reaction as described previously (Ma et al., 2006), whole mounted between two coverslips in PBS-glycerol, imaged from both sides, and reconstructed with Neurolucida (MicroBrightField) under 40X (dry) or $60 \times$ (water immersion) objectives.

\section{Results}

Guided by optogenetic stimulation of ChR2-expressing thalamocortical neurons in the VB thalamus (see Materials and Methods), we obtained paired wholecell recordings, with one neuron in $\mathrm{VB}$ and the other in the somatosensory (barrel) cortex (Fig. 1, diagram). Cortical neurons were identified as regular-spiking (RS; excitatory), fast-spiking (FS; inhibitory), or SOM (inhibitory) by their characteristic spike waveforms (Fig. $1 A-C$ ), firing patterns (Fig. $1 D-F$ ), and other electrophysiological parameters (Table 1), as done previously (Ma et al., 2006). Spike widths at half-height in the three cell types segregated into non-overlapping ranges $(0.71-1.33,0.26-0.35$, and $0.40-$ $0.58 \mathrm{~ms}$ in RS, FS, and SOM cells, respectively) and adaptation ratios segregated between FS and SOM interneurons (0.58-0.94 and 0.19-0.57, respectively). SOM cells were also genetically tagged by GFP, by breeding in the X94 line (Ma et al., 2006).

In nine layer $5 \mathrm{~b}$ neurons, including four RS, four FS, and one SOM neuron, a single thalamocortical action potential (Fig. 1G-I, red traces) elicited depolarizing responses at short $(<3 \mathrm{~ms})$ and lowjitter $(\mathrm{CV} \leq 0.11)$ latencies, indicating a unitary EPSP (uEPSP) elicited by a mono-

\section{$\longleftarrow$}

measurements of individual EPSP components $\left(E_{1}, E_{3}\right)$ and the peak burst response $\left(E_{\max }\right) \cdot \boldsymbol{Q}, \boldsymbol{R}$, Normalized amplitudes of individual bEPSP components; $E_{n}$ is the amplitude of the $n$th EPSP in the burst (measured as shown in $\boldsymbol{P}$ ). Each cell is represented by a thin line (example cell in blue) and sample average by a thick line. The "Cell-attached" plot in $\boldsymbol{R}$ refers to the recording shown in the inset in $\boldsymbol{L}$. Calibration (above $\boldsymbol{H}$, applies to $\mathbf{G}-\mathbf{0}): \mathbf{L}, \mathbf{0}, 1.5 \mathrm{mV}$; all other panels, $1 \mathrm{mV}$. 
Table 1. Average intrinsic electrophysiological parameters of the three cortical cell classes

\begin{tabular}{|c|c|c|c|c|c|c|c|c|}
\hline & $\begin{array}{l}\text { Age } \\
\text { (d) }\end{array}$ & $\begin{array}{l}V_{\text {rest }} \\
(\mathrm{mV})\end{array}$ & $\begin{array}{l}R_{\text {in }} \\
(\mathrm{M} \Omega)\end{array}$ & $\begin{array}{l}V_{\text {threshold }} \\
(\mathrm{mV})\end{array}$ & $\begin{array}{l}\text { Spike } \\
\text { height } \\
\text { (mV) }\end{array}$ & $\begin{array}{l}\text { Spike } \\
\text { width } \\
\text { (ms) }\end{array}$ & $\begin{array}{l}\text { AHP } \\
(\mathrm{mV})\end{array}$ & $\begin{array}{l}\text { Adaptation } \\
\text { ratio }\end{array}$ \\
\hline \multicolumn{9}{|l|}{$\begin{array}{c}\text { RS neurons } \\
n=8\end{array}$} \\
\hline Average & 18.5 & -66.5 & 135.3 & -37.6 & 78.7 & 0.91 & 6.2 & 0.38 \\
\hline SD & 2.6 & 3.4 & 49.4 & 5.0 & 11.3 & 0.20 & 6.7 & 0.3 \\
\hline \multicolumn{9}{|l|}{$\begin{array}{c}\text { FS interneurons } \\
n=13\end{array}$} \\
\hline Average & 18.6 & -63.8 & 67.7 & -39.8 & 66.0 & 0.31 & 14.6 & 0.74 \\
\hline SD & 2.2 & 2.5 & 20.5 & 4.0 & 10.0 & 0.03 & 2.8 & 0.13 \\
\hline \multicolumn{9}{|c|}{$\begin{array}{l}\text { SOM interneurons } \\
\quad n=6\end{array}$} \\
\hline Average & 19.5 & -61.7 & 149.2 & -39.8 & 62.2 & 0.50 & 10.5 & 0.41 \\
\hline SD & 2.2 & 2.4 & 62.3 & 1.5 & 14.2 & 0.07 & 4.3 & 0.14 \\
\hline
\end{tabular}

Table 2. Properties of unitary thalamocortical EPSPs

\begin{tabular}{llllll}
\hline Neuron ID & Latency (ms) & Latency CV & Amplitude $(\mathrm{mV})$ & Rise time $(\mathrm{ms})$ & Decay $\tau(\mathrm{ms})$ \\
\hline RS1 & 2.58 & 0.04 & 0.62 & 2.06 & 36.2 \\
RS2 & 2.43 & 0.11 & 0.92 & 2.81 & 16.7 \\
RS3 & 2.15 & & 0.62 & & \\
RS4 & 1.72 & 0.11 & 0.42 & 1.30 & 32.0 \\
Average & $\mathbf{2 . 2 2}$ & $\mathbf{0 . 0 8}$ & $\mathbf{0 . 6}$ & $\mathbf{2 . 0 6}$ & $\mathbf{2 8 . 3}$ \\
SD & $\mathbf{0 . 3 8}$ & $\mathbf{0 . 0 4}$ & $\mathbf{0 . 2}$ & $\mathbf{0 . 7 6}$ & $\mathbf{1 0 . 3}$ \\
FS1 & 2.01 & 0.04 & 1.78 & 0.36 & 10.1 \\
FS2 & 2.28 & 0.03 & 3.26 & 0.51 & 6.2 \\
FS3 & 1.22 & 0.02 & 13.77 & 0.64 & 5.9 \\
FS4 & 2.62 & 0.04 & 2.91 & 0.76 & 11.8 \\
Average & $\mathbf{2 . 0 3}$ & $\mathbf{0 . 0 3}$ & $\mathbf{5 . 4}$ & $\mathbf{0 . 5 7}$ & $\mathbf{8 . 5}$ \\
SD & $\mathbf{0 . 6 0}$ & $\mathbf{0 . 0 1}$ & $\mathbf{5 . 6}$ & $\mathbf{0 . 1 7}$ & $\mathbf{2 . 9}$ \\
Pvalue & $\mathbf{0 . 6 1}$ & $\mathbf{0 . 1 8}$ & $\mathbf{0 . 0 3}$ & $\mathbf{0 . 0 5}$ & $\mathbf{0 . 0 5}$ \\
SOM1 & 1.89 & 0.10 & 1.44 & 0.67 & 12.1 \\
\hline
\end{tabular}

For definition of parameters, see Materials and Methods. Summary statistics for each subtype are in bold. $p$ values are for the differences between RS and FS cells. The example cells in Fig. 1 are RS2, FS2, and SOM1 (italicized).

synaptic connection. Superimposed single sweeps and averaged uEPSPs from the three example neurons are shown in Figure $1 G-I$ (gray and blue traces, respectively); the characteristic parameters of each monosynaptic connection are summarized in Table 2 (the example neurons are RS2, FS2, and SOM1). In agreement with previous in vitro studies using extracellular stimulation of thalamocortical axons (Porter et al., 2001; Gabernet et al., 2005; Cruikshank et al., 2007), thalamocortical uEPSPs had several-fold larger amplitudes and faster kinetics in FS interneurons compared with excitatory neurons (amplitude, $1.8-13.8$ vs $0.4-0.9 \mathrm{mV}$; rise time, $0.4-0.8$ vs $1.3-2.8 \mathrm{~ms}$; decay time constant, $6-12$ vs $17-36 \mathrm{~ms})$. The SOM uEPSP had intermediate values of amplitude and kinetics $(1.4 \mathrm{mV}, 0.7$ and $12 \mathrm{~ms}$, respectively); thalamocortical uEPSPs in SOM interneurons have not been described previously. The SOM interneuron failed to respond in $17 \%$ of single-spike trials; no failures were observed in RS and FS cells. We reconstructed morphologically one thalamus-FS pair (FS2 in Table 2; Fig. 2). Examination under a highpower objective revealed five sites of close appositions between the presynaptic thalamocortical axon and postsynaptic FS dendrites (Fig. 2, black circles), consistent with an estimated average of four to six contacts ("hotspots") made by thalamocortical axons on FS interneurons (Bagnall et al., 2011).

To test the synaptic effect of thalamocortical bursts, we elicited in the thalamic neurons LTS-mediated bursts of three to six spikes, either on the offset of a hyperpolarizing current step or by a brief positive step from resting membrane potential (Fig. $1 J-L$, red traces). The first interspike interval (ISI; measured from peak to peak) in all bursts was $<4 \mathrm{~ms}$, but ISIs became progressively longer within each burst, as described previously (Domich et al., 1986). The postsynaptic cortical neurons responded to each burst with a sequence of summated EPSPs, which we refer to as burst EPSPs (bEPSPs). Superimposed single sweeps and averaged bEPSPs from the three example cells are shown in Figure $1 J-L$ (gray and blue traces, respectively). Averaged single-spike EPSPs and bEPSPs from the three example neurons are superimposed for comparison in Figure $1 M-O$ (blue and black traces, respectively; burst responses also indicated by arrows). In excitatory cells, the slow decay time constant resulted in a bEPSP without clearly distinct components (Fig. $1 J$ ) but with a higher peak amplitude and slower time course compared with the uEPSPs in the same cells (Fig. 1M). In contrast, bEPSPs in FS interneurons showed distinct peaks corresponding to individual spikes in the presynaptic burst (Fig. $1 K$; note vertical guidelines). However, because of their fast decay time constants, individual EPSPs have decayed considerably by the onset of the following ones. Moreover, individual EPSPs in FS cells underwent strong short-term depression during the burst, decrementing to $\sim 20 \%$ of their initial amplitude by the fourth EPSP (Fig. 1Q; when measuring individual EPSP amplitudes within a bEPSP, we corrected for both the decay time course of the previous EPSP and temporal dispersion attributable to presynaptic spike time jitter; see Materials and Methods and Fig. 1P). Together, these effects in FS cells resulted in a bEPSP that peaked on the response to the first or second spike in the burst. In the SOM interneuron, like in FS cells, the bEPSP consisted of clearly separable responses to individual spikes (Fig. $1 L$, vertical guidelines); however, the slower EPSP decay time constant and the absence of short-term depression (Fig. 1R, bottom plot) allowed these components to summate to more than twice the amplitude of the initial component, and the response usually peaked on the last EPSP in the burst. Interestingly, when stimulating the presynaptic thalamocortical cell in the cell-attached configuration, before rupturing the membrane patch (Fig. $1 L$, inset), the postsynaptic response in the SOM cell was strongly facilitating (Fig. $1 R$, top plot) and the failure rate of the first component was twofold higher ( 0.27 vs 0.13$)$, suggesting that release probability of the $\mathrm{VB} \rightarrow \mathrm{SOM}$ synapse in this pair has increased after establishing the whole-cell configuration.

To confirm and extend the results from connected thalamuscortex pairs, we elicited putative unitary thalamocortical bEPSPs in topologically aligned, but not monosynaptically connected, pairs. In these experiments, a $10-50 \mathrm{~ms}$ light pulse in the thalamus elicited in the thalamocortical neurons prolonged (several seconds) and rhythmic (3-5 Hz) barrages of IPSPs and occasional rebound bursts (Fig. $3 A-C$, red traces). This oscillatory activity most likely arose from the reciprocal connections between the VB and reticular thalamic nuclei, with the latter receiving excitatory inputs from, and providing strong inhibitory feedback to, thalamocortical neurons (Bando et al., 1980; von Krosigk et al., 1993; Huguenard and Prince, 1994; Warren et al., 1994). In the paired (but not synaptically connected) cortical neurons, the same brief stimulus elicited a short-latency excitatory response (Fig. 3A-C, blue traces, light blue arrows), presumably elicited by thalamocortical neurons directly activated by the light pulse, followed at variable latencies by one or more synaptic events (Fig. $3 A-C$, blue traces, black arrows), typically phase locked to the thalamic oscillation. Also, in some experiments, reducing the light stimulus to a minimum caused the initial (direct) synaptic response in the cortical neuron to shift in latency from trial to trial. Twenty superimposed trials from each example neuron are 
shown in Figure $3 D-F$, demonstrating the trial-to-trial jitter of these synaptic events (indicated by black arrows). However, aligning events in each cell by their onset revealed a highly stereotypical temporal pattern resembling a bEPSP (Fig. 3G-I, 20 superimposed responses in gray, averaged traces in blue; compare with Fig. $1 J-L)$. As we argue below, these stereotypical events were most likely monosynaptic responses to bursts fired by single thalamocortical neurons during rebound from inhibition, and we refer to them as rebound bEPSPs. We selected for additional analysis four RS, nine FS, and five SOM cells (all in layer 5b except for five FS cells in layer 4) with pronounced rebound responses. The short-term dynamics of rebound bEPSPs (Fig. $3 K, L$ ) were significantly different between FS and SOM interneurons $(p<$ 0.005 when comparing EPSPs of the same order in the two cell types) but were statistically indistinguishable $(p>0.6)$ from the dynamics of bEPSPs in connected pairs of the same subtype (Fig. 1Q,R). On average, rebound bEPSPs in FS cells strongly depressed, decrementing to $20 \%$ of their initial values by the fourth EPSP in the burst (Fig. $3 K$ ), identical to FS cells in connected pairs (Fig. 1Q). There were no significant differences in dynamics between layer 5 and layer 4 FS cells $(p>0.5$ for the second and third EPSPs, $p=0.15$ for the fourth EPSP). In contrast, the average rebound bEPSP in SOM cells was relatively stable in amplitude (Fig. 3L), similar to the whole-cell response of the connected SOM interneuron (Fig. $1 R$, bottom plot). However, note that, in one SOM cell (Fig. $3 L$, topmost plot), the rebound bEPSP strongly facilitated, resembling the cell-attached response of the connected SOM interneuron (Fig. $1 R$, top plot), whereas in two other cells, the response decremented by more than half its initial amplitude, suggesting a wide range of shortterm dynamics in the $\mathrm{VB} \rightarrow$ SOM synapse, reminiscent of the variable dynamics of excitatory inputs onto SOM interneurons in the hippocampus (Losonczy et al., 2002).

Although it is theoretically possible that some rebound bEPSPs were elicited by two or more thalamocortical neurons that fired in precise register over multiple trials, we submit that this was highly unlikely. Thalamocortical relay cells do not fire synchronously even when they rebound from synchronous IPSPs (Sohal et al., 2006; Pita-Almenar et al., 2014), and they lack synchronizing mechanisms such as gap junctions beyond the early postnatal period (Lee et al., 2010). Therefore, the most parsimonious explanation is that these precisely repeating responses were unitary bEPSPs, elicited by bursts in single thalamocortical axons. But could bEPSPs in a given cortical cell have been elicited, in different trials, by different thalamocortical neurons that happened to fire bursts with similar temporal patterns? To test this possibility, we compared temporal patterns of thalamocortical bursts and cortical bEPSPs.

We first measured ISIs of optogenetically elicited bursts with four or more spikes in thalamocortical relay neurons $(n=4$ cells and 55 rebound bursts). Plotting the first versus second ISI for each burst revealed three properties of LTS burst patterns (Fig. $4 A)$ : (1) the first and second ISIs were linearly dependent, so data points fell mostly along a straight line, which we termed "the main sequence"; (2) bursts from a given thalamocortical relay neuron clustered together, with relatively little overlap between the different cells; and (3) for a given cell, bursts with higher number of spikes clustered lower on the main sequence and with less scatter, so cells firing a variable number of spikes per burst were represented by more than one cluster (e.g., the two clusters of purple-coded data points in Figure $4 A$ correspond to bursts of four and five to six spikes in the same neuron). We then analyzed patterns of rebound bEPSP in FS interneurons in which the onsets of individual bEPSP components were unambiguous $(n=5$ cells, 101 bEPSPs). For each bEPSP, we plotted the first versus second inter-EPSP intervals (IEIs, measured onset to onset). Similar to presynaptic spike patterns, data points representing postsynaptic bEPSP patterns fell mostly along a diagonal line in cellspecific clusters, albeit with somewhat more scatter (Fig. 4B). Extreme outliers (two indicated by arrows in Fig. $4 B$, nine others are beyond the graph boundaries) could be explained either as bEPSPs in which the second EPSP failed (outliers above the main sequence) or bEPSPs in which apparent asynchronous neurotransmitter release generated supernumerary synaptic events (outliers below the main sequence). However, even without these outliers, considerable scatter remained. Jitter in synaptic latencies is inherent to vesicular neurotransmitter release (Sabatini and Regehr, 1999; Lisman et al., 2007); thus, one would expect postsynaptic events to be more scattered than the presynaptic spikes generating them. But how much scatter was to be expected, and was it enough to explain the scatter of rebound bEPSP patterns observed in Figure $4 B$ ?

As an independent measure of the expected postsynaptic scatter, we replicated the analysis described above on the subset of monosynaptically connected VB $\rightarrow$ FS pairs ( $n=4$ cells, 51 burst-bEPSP pairs). The presynaptic and postsynaptic patterns in the connected pairs (Fig. $4 C, D$ ) closely resembled the patterns in the nonconnected dataset (Fig. $4 A, B$ ), in both the near-linear trend and the amount of scatter. Indeed, superimposing the connected and nonconnected presynaptic plots (Fig. 4E, orange and blue data points, respectively) and separately superimposing the postsynaptic plots (Fig. 4F, same color code) revealed a nearly perfect overlap between the two datasets. Thus, the observed scatter in rebound bEPSP patterns was consistent with scatter expected from synaptic latency jitter. If so, one would expect that 
RS
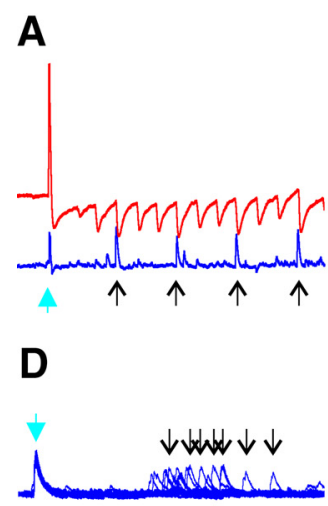

G

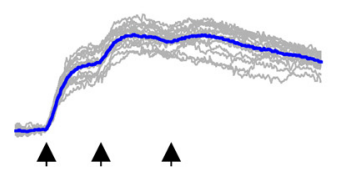

$\mathrm{J}$

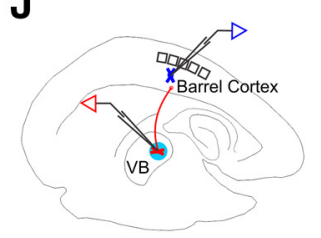

FS

SOM

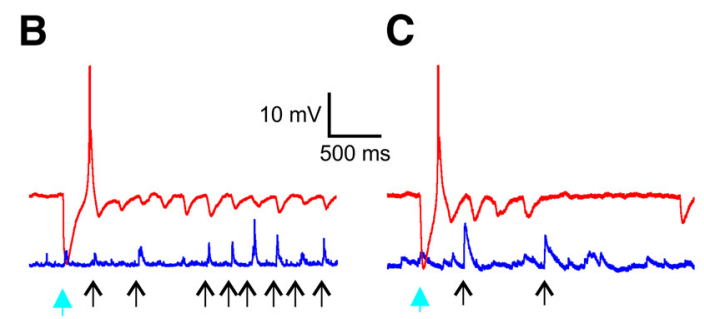

E

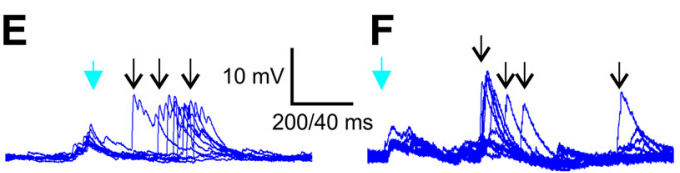

H

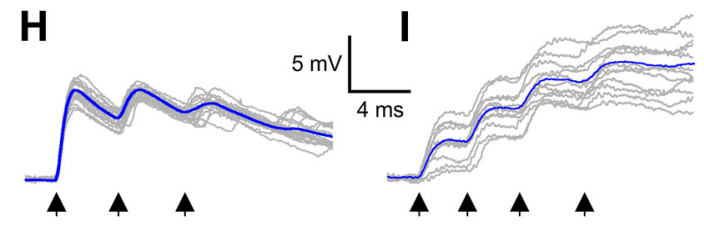

K
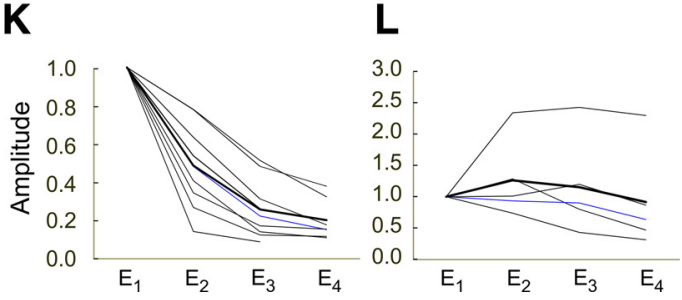

Figure 3. Rebound bEPSPs in the three cortical cell types. $\boldsymbol{A}-\boldsymbol{C}$, Paired recordings from topologically aligned but nonconnected thalamocortical (red) and cortical (blue) neurons during optogenetic stimulation in the thalamus. Spikes are truncated. The light blue arrows indicate the direct response to the light stimulus, and thin black arrows indicate rebound bEPSPs. D-F, Twenty superimposed trials, from the same example FS and SOM cells and a different RS cell. Arrows as in $A-C$. Note the variable latency of the rebound bEPSP. Horizontal calibration of $40 \mathrm{~ms}$ applies to $\boldsymbol{E}$. $\mathbf{G}-\boldsymbol{I}$, The same bEPSPs shown in $\boldsymbol{D}-\boldsymbol{F}$, aligned on their onset (superimposed single sweeps in gray, averages in blue). Note the reproducible temporal patterns, despite the variable latencies. Arrows indicate onset of apparent individual EPSPs. J, Diagram showing the dual recording configuration; light blue circle represents the stimulating light spot in the thalamus. $\boldsymbol{K}, \boldsymbol{L}$, Normalized amplitudes of individual bEPSP components (Fig. $1 P$ and Materials and Methods for details of measurements). Each cell is represented by a thin line (example cells in blue) and sample average by a thick line.

the data points in Figure $4 B$ would be randomly but symmetrically distributed around the data points in Figure $4 A$; however, superimposing the presynaptic and postsynaptic data points, in both the nonconnected and connected datasets, revealed that the postsynaptic patterns were slightly but consistently offset from the presynaptic main sequence (Fig. 4G,H). To examine the source of this offset, we measured latencies (spike peak to EPSP onset) of individual bEPSP components in the four monosynaptically connected FS interneurons. Average latencies of the second and third components were 0.46 and $0.55 \mathrm{~ms}$, respectively, longer than the latency of the first component. This can be explained by slower conduction velocity of later spikes in the burst ("subnormality"; Beierlein et al., 2003) and/or by slowing down of the vesicle fusion process attributable to the decrease in release probability and widening of spike waveforms during the burst (Boudkkazi et al., 2007, 2011). This increase in latency would lengthen the first and second IEIs by 0.46 and $0.1 \mathrm{~ms}$, on average, compared with the presynaptic ISIs. Consistent with this prediction, shifting the postsynaptic data points by $0.46 \mathrm{~ms}$ left and 0.1 ms down corrected the apparent offset in both datasets and brought the presynaptic and postsynaptic sequences into precise register (Fig. $4 I, J$ ). After this correction, the centers of mass of the presynaptic and postsynaptic data points in Figure $4 I$ overlapped precisely (at coordinates 3.3, $3.7 \mathrm{~ms}$ ), whereas the centers of mass in Figure $4 \mathrm{~J}$ overlapped in the $y$ dimension $(3.9 \mathrm{~ms})$ and were offset by only $0.2 \mathrm{~ms}$ in the $x$ dimension (3.3 vs $3.5 \mathrm{~ms}$, respectively). Together, these analyses are fully consistent with our assertion that rebound bEPSPs observed in a given cortical neuron were elicited by rebound bursts in the same presynaptic thalamocortical neuron.

Compared with their first spike, thalamocortical bursts could increase the firing probability of the postsynaptic neuron by generating a larger depolarization, thereby making it more likely that it would cross firing threshold. Assuming that the momentary membrane potential when an EPSP occurs is a randomly distributed variable, the probability that this EPSP will bring the membrane potential above firing threshold, i.e., the EPSP efficacy, is to a first approximation proportional to its peak amplitude. Therefore, the efficacy of a thalamocortical burst relative to the first spike in the burst can be estimated by $E_{\max } / E_{1}$, the ratio of the peak bEPSP amplitude to the amplitude of its first component; we refer to this ratio as the normalized bEPSP (bEPSP $\left.{ }_{\text {norm }}\right) . E_{1}$ and $E_{\max }$ values for each neuron are plotted in Figure $5 A$, with values from connected and nonconnected pairs indicated by filled and open symbols and connected by solid and dashed lines, respectively. The overall larger response amplitudes in nonconnected versus connected pairs likely reflected our bias in selecting cells with large rebound bEPSPs for analysis. However, bEPSP ${ }_{\text {norm }}$ values were not significantly different between the two datasets ( $p=0.20,0.58$, and 1 for RS, FS, and SOM cells, respectively). Therefore, we pooled bEPSP norm $_{\text {values by }}$ subtype (Fig. $5 B$ ). The average bEPSP ${ }_{\text {norm }}$ values were $2.1 \pm 0.5$ in RS cells $(n=8$; range, 1.5-3.6) and $2.5 \pm 0.4$ in SOM interneurons ( $n=6$; range, 1.6-3.6), reflecting the strong summation (and facilitation, in some SOM cells) of the synaptic response in the course of the burst. In contrast, average bEPSP $_{\text {norm }}$ in FS interneurons was only $1.1 \pm 0.1(n=13$; range, $1.0-1.3)$, because half the FS bEPSPs peaked on the first component (in which case bEPSP $_{\text {norm }}=1$ ) and the remaining bEPSPs peaked on the second component, which was not much higher than the first. Differences in bEPSP ${ }_{\text {norm }}$ between FS interneurons and either of the other two cell types were highly significant $(p<0.0001)$. Note

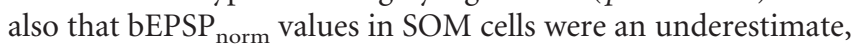
because $E_{\max }$ was measured on the averaged trace and was likely reduced by temporal jitter in presynaptic spike times. Because jitter was more pronounced in the late spikes in the burst (Fig. $1 J-L$, red traces), this error mostly affected SOM cells, whose response typically peaked on the third or later EPSPs. We con- 

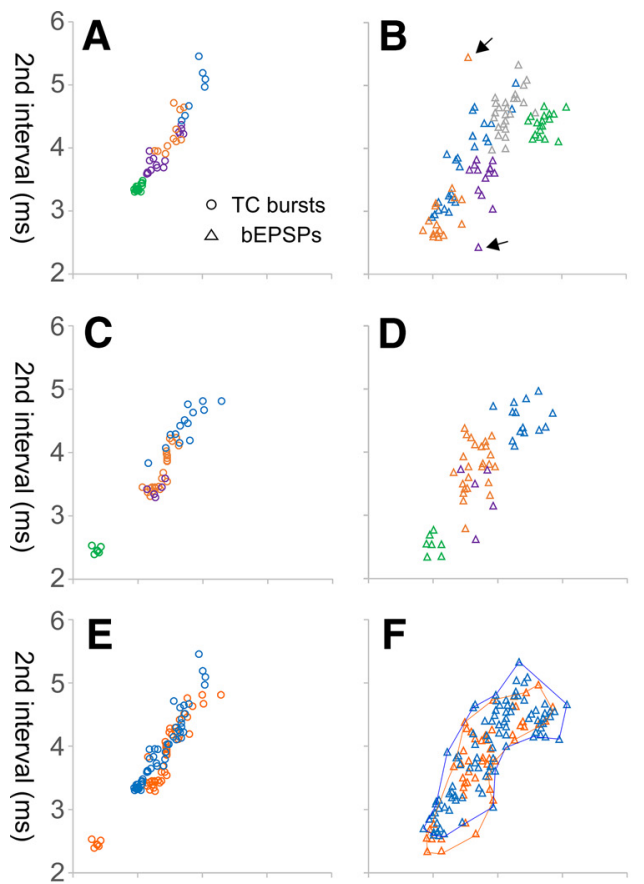

$6 \mathbf{G}$
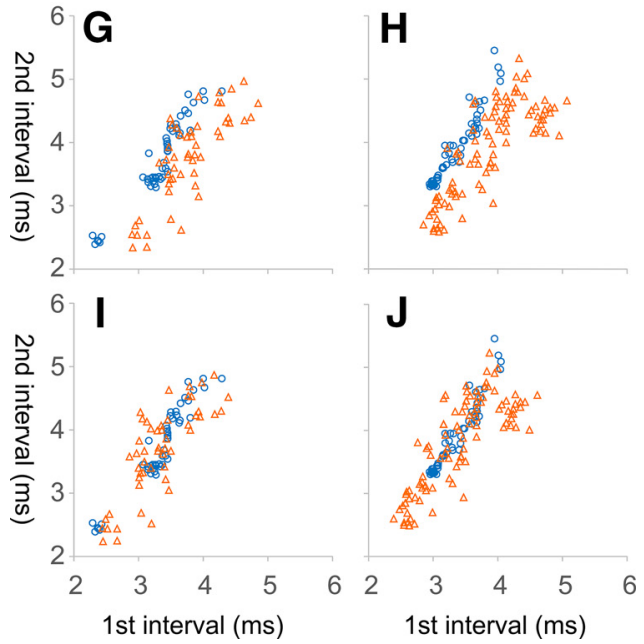

Figure 4. Comparison of presynaptic and postsynaptic burst patterns. A, Spike burst patterns (second ISI vs first ISI) in four thalamocortical (TC) neurons during optogenetically triggered rhythmic rebounds. Different cells are indicated in different colors. Note that some cells form more than one cluster. $\boldsymbol{B}$, Rebound bEPSP patterns (second interval vs first interval) in five FS interneurons, depicted in different colors. Cell-specific bEPSP clusters are more dispersed than spike clusters. $\boldsymbol{C}, \boldsymbol{D}$, Presynaptic and postsynaptic burst patterns in the four connected $\mathrm{VB} \rightarrow \mathrm{FS}$ pairs. $\boldsymbol{E}, \boldsymbol{F}$, Superposition of $\boldsymbol{A}$ and $\boldsymbol{C}$ and of $\boldsymbol{B}$ and $\boldsymbol{D}$, respectively; the continuous outlines in $\boldsymbol{F}$ connect the outermost data points in each cluster and demonstrate the close overlap between burst patterns in the connected and nonconnected datasets. $\mathbf{G}, \boldsymbol{H}$, Superposition of $\boldsymbol{C}$ and $\boldsymbol{D}$ and of $\boldsymbol{A}$ and $\boldsymbol{B}$, respectively. Offset between presynaptic and postsynaptic patterns is attributable to slowing down of axonal conduction and/or of vesicle release after the first spike in the burst. $I, J$, Correcting for the increased latencies brings presynaptic and postsynaptic patterns into precise register.

clude that, compared with the first spike in the burst, a unitary thalamocortical burst is more than twofold more likely to fire RS cells and SOM interneurons but only $\sim 10 \%$ more likely to fire FS cells.

If bursts more than double the probability of firing relative to the first spike, one would expect to observe bEPSP-evoked spikes occurring more frequently on the second or later components of the bEPSP than on the first. Conversely, if bursts do not increase firing probability significantly, most bEPSP-evoked spikes should be

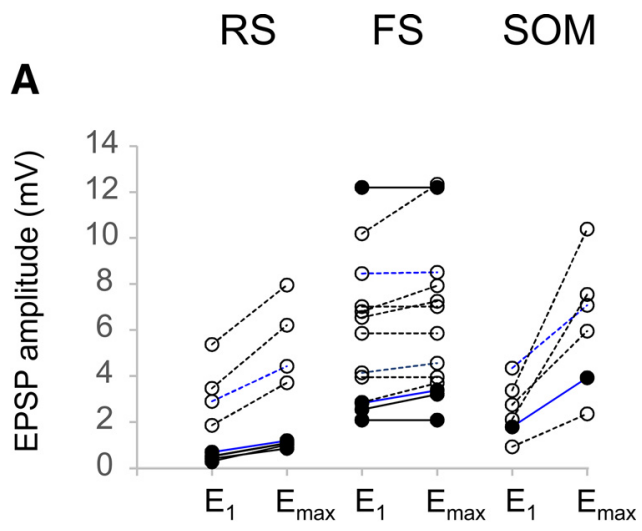

B

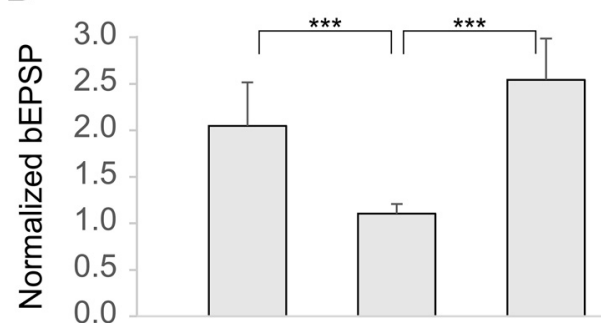

Figure 5. Amplitudes of bEPSPs in the three cortical cell types. $\boldsymbol{A}$, For each cell, average amplitude of the first component $\left(E_{1}\right)$ and the peak of the $\operatorname{bEPSP}\left(E_{\mathrm{max}}\right)$ are indicated by circles connected by a line (refer to Fig. $1 P$ for definitions). Solid lines and filled symbols indicate data from synaptically connected thalamus-cortex pairs, and dashed lines and open symbols represent nonconnected cortical neurons; blue lines represent example neurons from Figures 1 and 3. B, Average normalized bEPSP $\left(E_{\max } / E_{1}\right)$ for each cell type, pooled from both connected and nonconnected pairs; $n=8,13$, and 6 for RS, FS, and SOM, respectively. Error bars indicate SEM. Significance brackets indicate ${ }^{* *} p<0.0001$.

triggered by the first component. We tested this prediction by optogenetically eliciting rebound bEPSPs in six FS and three SOM cells depolarized to near-threshold (only bEPSPs with clearly identifiable components were included in this analysis; bEPSPs in RS cells had indistinct components and were therefore not included). Only one FS cell fired more often on the second than on the first EPSP ( 41 vs $24 \%$ of the time); the remaining five cells fired most often on the first EPSP, as illustrated in Figure 6, $A$ and $C$, and quantified in Figure $6 F$. In contrast, SOM cells held at equivalent membrane potentials fired on the second or later EPSPs, almost never on the first (Fig. $6 B, D, G$ ). On average, $75 \pm$ $12 \%$ of bEPSP-evoked spikes in FS interneurons, but only $2 \pm 2 \%$ in SOM interneurons, were triggered by the first EPSP $(p=$ 0.007). Therefore, these data support the conclusion that, relative to the initial spike in the burst, thalamocortical bursts strongly enhance firing probability in SOM, but not in FS, interneurons.

The rationale underlying the conclusion above would fail if bursts elicited more than one spike, for example, if a spike occurred on the first EPSP and also on a later EPSP within the same burst. This would allow bursts to increase postsynaptic firing probability even without a concomitant increase in the peak bEPSP amplitude. A priori, one might expect that this would be the case in FS interneurons, which are known to fire highfrequency bursts when stimulated synaptically (McCormick et al., 1985; Swadlow, 1988). If so, then bursts would have a stronger effect on FS cells than we estimated from their average bEPSP $_{\text {norm }}$. Therefore, we examined the same subset of six FS interneurons held at near-threshold membrane potentials for occurrence of more than one spike per bEPSP. Such occurrence was observed in only one FS cell. This neuron (the same cell that fired 
FS

SOM
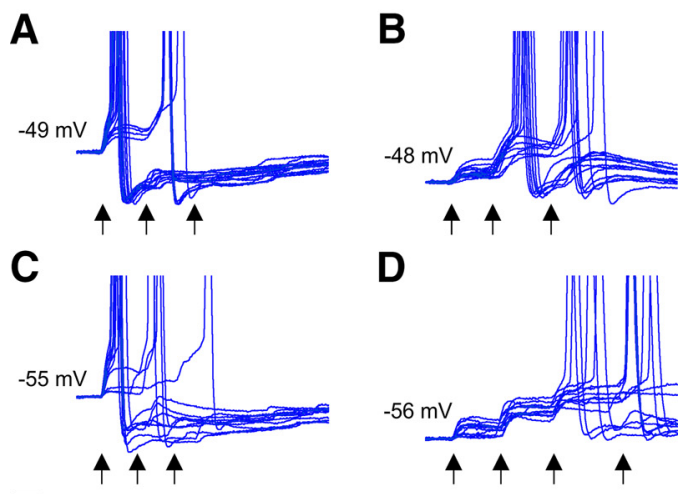

$\mathbf{E}$
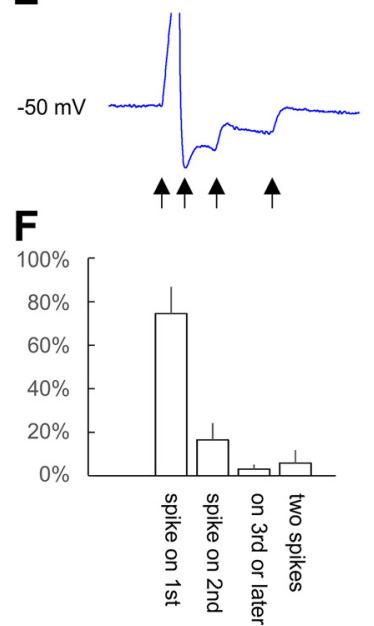

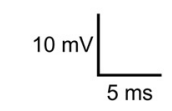

G

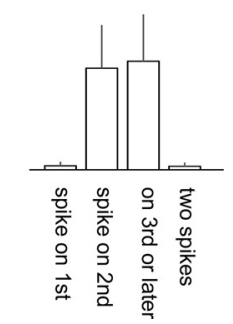

Figure 6. Burst-elicited spikes in FS and SOM interneurons. A-D, Suprathreshold bEPSPs in FS and SOM interneurons held at depolarized membrane potentials (holding potential indicated to the left of each panel). Multiple bEPSPs are aligned on their onset and superimposed. Note that FS cells fired most often on the first EPSP in the burst, whereas SOM interneurons fired only on the second or later EPSPs. E, A single-sweep suprathreshold FS bEPSP illustrating how the deep AHP after the initial spike preempted subsequent EPSPs from crossing threshold. Arrows indicate onset of the individual components of the bEPSP. Spikes in $\boldsymbol{A}-\boldsymbol{E}$ are truncated. $\boldsymbol{F}, \boldsymbol{G}$, Average fraction of suprathreshold bEPSPs that elicited spikes on the first, second, or third or later components or that elicited more than one spike. Error bars are SEM.

more often on the second EPSP) had an exceptionally large rebound bEPSP $(12.3 \mathrm{mV})$ that peaked on the second component; in 35\% of suprathreshold bEPSPs, it fired on both the first and second components, although in no case did it fire more than two spikes per bEPSP. The remaining five FS cells fired only a single spike per burst, as did the three SOM cells (Fig. 6F, G, rightmost bars). Examination of individual suprathreshold FS bEPSPs revealed the underlying reason: the first postsynaptic spike ended with a large afterhyperpolarization (AHP), typical of FS cells. This AHP was sufficiently deep and prolonged to prevent any subsequent EPSPs in the burst, already reduced compared with the first because of short-term depression, from crossing threshold (Fig. 6E). Interestingly, unitary thalamocortical bursts in vivo also elicit more than one spike in FS cells only when the unitary connection is exceptionally strong (Swadlow and Gusev, 2001).

\section{Discussion}

We examined the synaptic responses of 27 cortical neurons to unitary (single-axon) thalamocortical bursts. We found that, compared with its initial spike, a thalamocortical burst elicited more than twofold larger depolarization, on average, in excit-

atory cells and SOM interneurons, but not in FS interneurons (Fig. $5 B$ ). This happened because the slow EPSP decay time constant in RS and SOM cells (Table 2), relative to the short intraburst ISIs, enabled temporal summation (Kim and McCormick, 1998; Usrey et al., 2000) and also (in SOM cells) because of the absence, on average, of short-term depression (Figs. $1 R, 3 L$; Beierlein et al., 2003; Minneci et al., 2007; Tan et al., 2008; Takesian et al., 2013). In RS and SOM cells, bEPSPs usually peaked on the late components of the burst response (Figs. $1 L, 3 I$ ). In contrast, the fast decay of EPSPs in FS interneurons (Table 2) combined with their pronounced short-term depression (Fig. 1Q, 3K; Galarreta and Hestrin, 1998; González-Burgos et al., 2004; Gabernet et al., 2005; Kloc and Maffei, 2014) caused bEPSPs in FS cells to peak on the first or second components of the response (Figs. $1 K, 3 H$ ). These differences were also reflected in the relative efficacy of the different burst components in triggering spikes. In SOM cells held close to firing threshold, spikes were elicited almost always by the second or later EPSPs in the burst (Fig. $6 G$ ), indicating that, compared with the initial spike, bursts strongly increased postsynaptic firing probability. In contrast, spikes in FS interneurons were mostly ( $75 \%$ of the time) elicited by the first EPSP (Fig. $6 F$ ), indicating that most bursts were not more effective than their first spike in activating FS cells. Last, once a spike was elicited in an FS cell, subsequent EPSPs in the same burst were usually too weak to overcome the characteristically deep AHP (Fig. 6E), and only exceptionally large bEPSPs could elicit more than one spike (Fig. $6 F$ ). Together, these results imply that, all else being equal, firing a thalamocortical burst instead of a single spike would increase firing probability by twofold or more in postsynaptic principal cells and in distally targeting SOM interneurons but will only slightly increase firing probability in proximally targeting FS interneurons. Note that this does not mean that the absolute effect of bursts is stronger on SOM interneurons than on FS cells; indeed, the EPSPs elicited in FS interneurons by single thalamocortical spikes were much larger than in either RS cells or SOM interneurons (Table 2). The burstmediated enhancement of the response in RS and SOM cells reduced this disparity but did not eliminate it (Fig. 5A).

What would be the functional outcome of the transient increase in excitation of principal neurons? In sensory cortical areas, incoming excitation is closely followed by precisely timed and proportionally scaled FS-mediated feedforward inhibition, thereby ensuring a linear response with a wide dynamic range, as well as a precisely timed window for postsynaptic firing (Porter et al., 2001; Wehr and Zador, 2003; Gabernet et al., 2005; Cruikshank et al., 2007). By increasing excitation of RS cells without a concomitant increase in FS-mediated feedforward inhibition, a thalamocortical burst will transiently widen the somatic integration window, increasing response probability (thus ensuring better detectability) at the expense of a larger temporal jitter (hence decreasing response precision), in agreement with the "wakeup call" hypothesis (Sherman, 2001). However, our results extend this hypothesis in an important way by showing that bursts would also enhance SOM-mediated distal inhibition. How would preferential enhancement of SOM-mediated inhibition affect cortical computations? An important target of infragranular SOM interneurons are the apical dendrites and tufts of pyramidal cells in upper cortical layers (Kawaguchi and Kubota, 1996; Wang et al., 2004; Silberberg and Markram, 2007; Ramos-Moreno and Clascá, 2014). One possible effect of burst-enhanced dendritic inhibition would be to uncouple layer 5 pyramidal cell bodies from inputs impinging on their apical dendritic tufts (Gidon and Segev, 2012). Many upper-layer inputs arise from intralaminar or 
higher-order thalamic nuclei (Rubio-Garrido et al., 2009; Cruikshank et al., 2012) or from higher-order cortical areas (Gonchar and Burkhalter, 2003) and thus represent top-down feedback relaying brain-state-dependent behavioral context (Gilbert and Sigman, 2007). Bursts would suppress this modulatory influence but allow infragranular pyramidal cells to respond to the novel and potentially more urgent sensory stimulus arriving from the thalamus by sending a signal subcortically (e.g., to spinal cord or tectum) and recruit an appropriate motor response.

Our conclusions are based on cortical responses to unitary thalamocortical bursts under the controlled conditions of a reduced in vitro preparation. Under in vivo conditions, with physiologically relevant firing rates and patterns, the efficacy of a thalamocortical burst would be the product of two independent factors: (1) the efficacy of its first spike; and (2) the efficacy of the burst relative to its first spike. Thalamocortical neurons in vivo tend to fire a burst after a period of quiescence, because a relatively prolonged hyperpolarization is required to de-inactivate the low-threshold Ca channels that underlie the burst (Sherman, 2001; Llinás and Steriade, 2006). The same prolonged quiescence also allows the thalamocortical synapses to recover from chronic short-term depression (Castro-Alamancos and Oldford, 2002; Swadlow et al., 2005). In FS interneurons, this recovery from depression increases the efficacy of the first spike in the burst by approximately twofold compared with the average spike efficacy, although not when compared with single spikes with equivalent preceding latencies (Swadlow and Gusev, 2001). In our analysis, we specifically removed any differential effects of the preburst latency by normalizing each bEPSP to its own first component. Thus, our results could be considered complementary to those of Swadlow and Gusev: whereas they examined the factors influencing the efficacy of the first spike in a thalamocortical burst, we analyzed the efficacy of the burst relative to its first spike. Both sets of data are needed for a full understanding of the effect of thalamocortical bursts under physiological conditions.

Our analysis was restricted to the effect of single thalamocortical axons and suggested that a unitary burst rarely elicits more than one spike in a postsynaptic FS interneuron. However, in vivo, multiple thalamocortical axons often fire synchronously (Alonso et al., 1996; Temereanca et al., 2008; Wang et al., 2010). If multiple thalamocortical axons converge on each FS interneuron (Bruno and Simons, 2002; Swadlow and Gusev, 2002; Inoue and Imoto, 2006; Cruikshank et al., 2007), a synchronous volley of thalamocortical bursts may elicit multiple spikes in the postsynaptic FS interneuron, enhancing burst efficacy beyond what we observed here. Furthermore, if thalamocortical convergence on FS interneurons is significantly higher than on SOM interneurons, the relative advantage of bursts in firing SOM interneurons may be reduced or negated.

Given the critical role of the thalamocortical synapse in cortical function and dysfunction and the large existing body of research into its properties, it may come as a surprise that this is the first report of dual intracellular recordings of synaptic connections from the thalamus to cortex (but note that monosynaptically connected pairs in the reciprocal direction were reported previously by Golshani et al., 2001). Presumptive unitary thalamocortical responses in RS and FS cells, but not in SOM interneurons, were previously studied in vitro using extracellular "minimal" stimulation (Stratford et al., 1996; Gil et al., 1999; Gabernet et al., 2005; Inoue and Imoto, 2006; Cruikshank et al., 2007; Hull et al., 2009). This method entails several unresolved caveats, including the possibility of unknowingly coactivating two or more axons with identical thresholds, the uncertainty in the identity of the stimulated axons (thalamocortical or corticothalamic), and the ambiguous nature of "failures" (failed conduction or failed transmission). Dual intracellular recording eliminates these uncertainties. Unitary single-spike and burst responses in excitatory cortical neurons were also examined in vivo by averaging postsynaptic responses triggered on extracellularly recorded thalamocortical spikes (Bruno and Sakmann, 2006); although overall consistent with our results, this study did not record from inhibitory interneurons.

Our dataset of connected thalamus-cortex pairs is still small and clearly not fully representative of all thalamocortical connections. Notably, we were unsuccessful to date in recording from monosynaptically connected neurons in layer 4, the main thalamo-recipient layer. This may reflect the reduced likelihood of preserving in vitro an intact axon extending from the thalamus to layer 4 compared with the shorter path to layer 5. Also, we have only one connected SOM interneuron in our sample to date. This could reflect the relative scarcity of this cell type but could also reflect a lower thalamic connection probability onto SOM, relative to FS, cells as suggested previously (Gibson et al., 1999). These gaps in our data could be filled by future higherthroughput experiments, using improved technologies such as two-photon laser stimulation with single-cell resolution (Packer et al., 2015). The above limitations notwithstanding, our results provide the first "ground truth" data on the electrophysiological properties of unitary thalamocortical synaptic connections, against which results acquired by the less direct methods mentioned above can now be assessed. Beyond the current findings, our results open this crucially important synapse to additional studies of its function, structure, and development at an unprecedented level of detail.

\section{References}

Agmon A, Connors BW (1991) Thalamocortical responses of mouse somatosensory (barrel) cortex in vitro. Neuroscience 41:365-379. CrossRef Medline

Alonso JM, Usrey WM, Reid RC (1996) Precisely correlated firing in cells of the lateral geniculate nucleus. Nature 383:815-819. CrossRef Medline

Bagnall MW, Hull C, Bushong EA, Ellisman MH, Scanziani M (2011) Multiple clusters of release sites formed by individual thalamic afferents onto cortical interneurons ensure reliable transmission. Neuron 71:180-194. CrossRef Medline

Bando T, Zambelli A, Spencer WA (1980) Rebound excitation and the rhythmic activity of the ventrobasal complex of the thalamus. Brain Res 192:29-38. CrossRef Medline

Beierlein M, Connors BW (2002) Short-term dynamics of thalamocortical and intracortical synapses onto layer 6 neurons in neocortex. J Neurophysiol 88:1924-1932. Medline

Beierlein M, Gibson JR, Connors BW (2003) Two dynamically distinct inhibitory networks in layer 4 of the neocortex. J Neurophysiol 90:29873000. CrossRef Medline

Bezdudnaya T, Cano M, Bereshpolova Y, Stoelzel CR, Alonso JM, Swadlow HA (2006) Thalamic burst mode and inattention in the awake LGNd. Neuron 49:421-432. CrossRef Medline

Boudkkazi S, Carlier E, Ankri N, Caillard O, Giraud P, Fronzaroli-Molinieres L, Debanne D (2007) Release-dependent variations in synaptic latency: a putative code for short- and long-term synaptic dynamics. Neuron 56:1048-1060. CrossRef Medline

Boudkkazi S, Fronzaroli-Molinieres L, Debanne D (2011) Presynaptic action potential waveform determines cortical synaptic latency. J Physiol 589:1117-1131. CrossRef Medline

Bruno RM, Sakmann B (2006) Cortex is driven by weak but synchronously active thalamocortical synapses. Science 312:1622-1627. CrossRef Medline

Bruno RM, Simons DJ (2002) Feedforward mechanisms of excitatory and inhibitory cortical receptive fields. J Neurosci 22:10966-10975. Medline

Castro-Alamancos MA, Oldford E (2002) Cortical sensory suppression during arousal is due to the activity-dependent depression of thalamocortical synapses. J Physiol 541:319-331. CrossRef Medline 
Chung S, Li X, Nelson SB (2002) Short-term depression at thalamocortical synapses contributes to rapid adaptation of cortical sensory responses in vivo. Neuron 34:437-446. CrossRef Medline

Coulter DA, Huguenard JR, Prince DA (1989) Calcium currents in rat thalamocortical relay neurones: kinetic properties of the transient, lowthreshold current. J Physiol 414:587-604. CrossRef Medline

Cruikshank SJ, Lewis TJ, Connors BW (2007) Synaptic basis for intense thalamocortical activation of feedforward inhibitory cells in neocortex. Nat Neurosci 10:462-468. CrossRef Medline

Cruikshank SJ, Ahmed OJ, Stevens TR, Patrick SL, Gonzalez AN, Elmaleh M, Connors BW (2012) Thalamic control of layer 1 circuits in prefrontal cortex. J Neurosci 32:17813-17823. CrossRef Medline

Domich L, Oakson G, Steriade M (1986) Thalamic burst patterns in the naturally sleeping cat: a comparison between cortically projecting and reticularis neurones. J Physiol 379:429-449. CrossRef Medline

Fanselow EE, Sameshima K, Baccala LA, Nicolelis MA (2001) Thalamic bursting in rats during different awake behavioral states. Proc Natl Acad Sci U S A 98:15330-15335. CrossRef Medline

Gabernet L, Jadhav SP, Feldman DE, Carandini M, Scanziani M (2005) Somatosensory integration controlled by dynamic thalamocortical feedforward inhibition. Neuron 48:315-327. CrossRef Medline

Galarreta M, Hestrin S (1998) Frequency-dependent synaptic depression and the balance of excitation and inhibition in the neocortex. Nat Neurosci 1:587-594. CrossRef Medline

Gerfen CR, Paletzki R, Heintz N (2013) GENSAT BAC cre-recombinase driver lines to study the functional organization of cerebral cortical and basal ganglia circuits. Neuron 80:1368-1383. CrossRef Medline

Gibson JR, Beierlein M, Connors BW (1999) Two networks of electrically coupled inhibitory neurons in neocortex. Nature 402:75-79. CrossRef Medline

Gidon A, Segev I (2012) Principles governing the operation of synaptic inhibition in dendrites. Neuron 75:330-341. CrossRef Medline

Gil Z, Connors BW, Amitai Y (1999) Efficacy of thalamocortical and intracortical synaptic connections: quanta, innervation, and reliability. Neuron 23:385-397. CrossRef Medline

Gilbert CD, Sigman M (2007) Brain states: top-down influences in sensory processing. Neuron 54:677-696. CrossRef Medline

Golshani P, Liu XB, Jones EG (2001) Differences in quantal amplitude reflect GluR4-subunit number at corticothalamic synapses on two populations of thalamic neurons. Proc Natl Acad Sci U S A 98:4172-4177. CrossRef Medline

Gonchar Y, Burkhalter A (2003) Distinct GABAergic targets of feedforward and feedback connections between lower and higher areas of rat visual cortex. J Neurosci 23:10904-10912. Medline

González-Burgos G, Krimer LS, Urban NN, Barrionuevo G, Lewis DA (2004) Synaptic efficacy during repetitive activation of excitatory inputs in primate dorsolateral prefrontal cortex. Cereb Cortex 14:530-542. CrossRef Medline

Guido W, Weyand T (1995) Burst responses in thalamic relay cells of the awake behaving cat. J Neurophysiol 74:1782-1786. Medline

Guido W, Lu SM, Vaughan JW, Godwin DW, Sherman SM (1995) Receiver operating characteristic (ROC) analysis of neurons in the cat's lateral geniculate nucleus during tonic and burst response mode. Vis Neurosci 12:723-741. CrossRef Medline

Huguenard JR, Prince DA (1994) Intrathalamic rhythmicity studied in vitro: nominal T-current modulation causes robust antioscillatory effects. J Neurosci 14:5485-5502. Medline

Hull C, Isaacson JS, Scanziani M (2009) Postsynaptic mechanisms govern the differential excitation of cortical neurons by thalamic inputs. J Neurosci 29:9127-9136. CrossRef Medline

Inoue T, Imoto K (2006) Feedforward inhibitory connections from multiple thalamic cells to multiple regular-spiking cells in layer 4 of the somatosensory cortex. J Neurophysiol 96:1746-1754. CrossRef Medline

Jahnsen H, Llinás R (1984) Electrophysiological properties of guinea-pig thalamic neurones: an in vitro study. J Physiol 349:205-226. CrossRef Medline

Kawaguchi Y, Kubota Y (1996) Physiological and morphological identification of somatostatin- or vasoactive intestinal polypeptide-containing cells among GABAergic cell subtypes in rat frontal cortex. J Neurosci 16:27012715. Medline

Kim U, McCormick DA (1998) The functional influence of burst and tonic firing mode on synaptic interactions in the thalamus. J Neurosci 18:95009516. Medline

Kloc M, Maffei A (2014) Target-specific properties of thalamocortical synapses onto layer 4 of mouse primary visual cortex. J Neurosci 34: 15455-15465. CrossRef Medline

Krahe R, Gabbiani F (2004) Burst firing in sensory systems. Nat Rev Neurosci 5:13-23. CrossRef Medline

Lee SC, Cruikshank SJ, Connors BW (2010) Electrical and chemical synapses between relay neurons in developing thalamus. J Physiol 588:24032415. CrossRef Medline

Lesica NA, Stanley GB (2004) Encoding of natural scene movies by tonic and burst spikes in the lateral geniculate nucleus. J Neurosci 24:1073110740. CrossRef Medline

Lisman JE, Raghavachari S, Tsien RW (2007) The sequence of events that underlie quantal transmission at central glutamatergic synapses. Nat Rev Neurosci 8:597-609. CrossRef Medline

Llinás RR, Steriade M (2006) Bursting of thalamic neurons and states of vigilance. J Neurophysiol 95:3297-3308. CrossRef Medline

Losonczy A, Zhang L, Shigemoto R, Somogyi P, Nusser Z (2002) Cell type dependence and variability in the short-term plasticity of EPSCs in identified mouse hippocampal interneurones. J Physiol 542:193-210. CrossRef Medline

Lu SM, Guido W, Sherman SM (1992) Effects of membrane voltage on receptive field properties of lateral geniculate neurons in the cat: contributions of the low-threshold Ca2 + conductance. J Neurophysiol 68: 2185-2198. Medline

Ma Y, Hu H, Berrebi AS, Mathers PH, Agmon A (2006) Distinct subtypes of somatostatin-containing neocortical interneurons revealed in transgenic mice. J Neurosci 26:5069-5082. CrossRef Medline

Madisen L, Mao T, Koch H, Zhuo JM, Berenyi A, Fujisawa S, Hsu YW, Garcia AJ 3rd, Gu X, Zanella S, Kidney J, Gu H, Mao Y, Hooks BM, Boyden ES, Buzsáki G, Ramirez JM, Jones AR, Svoboda K, Han X, Turner EE, Zeng H (2012) A toolbox of Cre-dependent optogenetic transgenic mice for light-induced activation and silencing. Nat Neurosci 15:793-802. CrossRef Medline

Martinez-Conde S, Macknik SL, Hubel DH (2002) The function of bursts of spikes during visual fixation in the awake primate lateral geniculate nucleus and primary visual cortex. Proc Natl Acad Sci U S A 99:1392013925. CrossRef Medline

McCormick DA, Connors BW, Lighthall JW, Prince DA (1985) Comparative electrophysiology of pyramidal and sparsely spiny stellate neurons of the neocortex. J Neurophysiol 54:782-806. Medline

Minneci F, Janahmadi M, Migliore M, Dragicevic N, Avossa D, Cherubini E (2007) Signaling properties of stratum oriens interneurons in the hippocampus of transgenic mice expressing EGFP in a subset of somatostatincontaining cells. Hippocampus 17:538-553. CrossRef Medline

Packer AM, Russell LE, Dalgleish HW, Häusser M (2015) Simultaneous alloptical manipulation and recording of neural circuit activity with cellular resolution in vivo. Nat Methods 12:140-146. CrossRef Medline

Pita-Almenar JD, Yu D, Lu HC, Beierlein M (2014) Mechanisms underlying desynchronization of cholinergic-evoked thalamic network activity. J Neurosci 34:14463-14474. CrossRef Medline

Porter JT, Johnson CK, Agmon A (2001) Diverse types of interneurons generate thalamus-evoked feedforward inhibition in the mouse barrel cortex. J Neurosci 21:2699-2710. Medline

Ramcharan EJ, Cox CL, Zhan XJ, Sherman SM, Gnadt JW (2000) Cellular mechanisms underlying activity patterns in the monkey thalamus during visual behavior. J Neurophysiol 84:1982-1987. Medline

Ramos-Moreno T, Clascá F (2014) Quantitative mapping of the local and extrinsic sources of GABA and Reelin to the layer Ia neuropil in the adult rat neocortex. Brain Struct Funct 219:1639-1657. CrossRef Medline

Reinagel P, Godwin D, Sherman SM, Koch C (1999) Encoding of visual information by LGN bursts. J Neurophysiol 81:2558-2569. Medline

Rubio-Garrido P, Pérez-de-Manzo F, Porrero C, Galazo MJ, Clascá F (2009) Thalamic input to distal apical dendrites in neocortical layer 1 is massive and highly convergent. Cereb Cortex 19:2380-2395. CrossRef Medline

Sabatini BL, Regehr WG (1999) Timing of synaptic transmission. Annu Rev Physiol 61:521-542. CrossRef Medline

Sherman SM (2001) Tonic and burst firing: dual modes of thalamocortical relay. Trends Neurosci 24:122-126. CrossRef Medline

Silberberg G, Markram H (2007) Disynaptic inhibition between neocortical 
pyramidal cells mediated by Martinotti cells. Neuron 53:735-746. CrossRef Medline

Sohal VS, Pangratz-Fuehrer S, Rudolph U, Huguenard JR (2006) Intrinsic and synaptic dynamics interact to generate emergent patterns of rhythmic bursting in thalamocortical neurons. J Neurosci 26:4247-4255. CrossRef Medline

Steriade M, McCormick DA, Sejnowski TJ (1993) Thalamocortical oscillations in the sleeping and aroused brain. Science 262:679-685. CrossRef Medline

Stratford KJ, Tarczy-Hornoch K, Martin KA, Bannister NJ, Jack JJ (1996) Excitatory synaptic inputs to spiny stellate cells in cat visual cortex. Nature 382:258-261. CrossRef Medline

Sun QQ, Huguenard JR, Prince DA (2006) Barrel cortex microcircuits: thalamocortical feedforward inhibition in spiny stellate cells is mediated by a small number of fast-spiking interneurons. J Neurosci 26:1219-1230. CrossRef Medline

Swadlow HA (1988) Efferent neurons and suspected interneurons in binocular visual cortex of the awake rabbit: receptive fields and binocular properties. J Neurophysiol 59:1162-1187. Medline

Swadlow HA, Gusev AG (2001) The impact of 'bursting' thalamic impulses at a neocortical synapse. Nat Neurosci 4:402-408. CrossRef Medline

Swadlow HA, Gusev AG (2002) Receptive-field construction in cortical inhibitory interneurons. Nat Neurosci 5:403-404. CrossRef Medline

Swadlow HA, Gusev AG, Bezdudnaya T (2002) Activation of a cortical column by a thalamocortical impulse. J Neurosci 22:7766-7773. Medline

Swadlow HA, Bezdudnaya T, Gusev AG (2005) Spike timing and synaptic dynamics at the awake thalamocortical synapse. Prog Brain Res 149:91105. CrossRef Medline

Takesian AE, Kotak VC, Sharma N, Sanes DH (2013) Hearing loss differentially affects thalamic drive to two cortical interneuron subtypes. J Neurophysiol 110:999-1008. CrossRef Medline

Tan Z, Hu H, Huang ZJ, Agmon A (2008) Robust but delayed thalamocortical activation of dendritic-targeting inhibitory interneurons. Proc Natl Acad Sci U S A 105:2187-2192. CrossRef Medline
Temereanca S, Brown EN, Simons DJ (2008) Rapid changes in thalamic firing synchrony during repetitive whisker stimulation. J Neurosci 28: 11153-11164. CrossRef Medline

Usrey WM, Alonso JM, Reid RC (2000) Synaptic interactions between thalamic inputs to simple cells in cat visual cortex. J Neurosci 20:5461-5467. Medline

von Krosigk M, Bal T, McCormick DA (1993) Cellular mechanisms of a synchronized oscillation in the thalamus. Science 261:361-364. CrossRef Medline

Wang Q, Webber RM, Stanley GB (2010) Thalamic synchrony and the adaptive gating of information flow to cortex. Nat Neurosci 13:15341541. CrossRef Medline

Wang XJ, Rinzel J, Rogawski MA (1991) A model of the T-type calcium current and the low-threshold spike in thalamic neurons. J Neurophysiol 66:839-850. Medline

Wang Y, Toledo-Rodriguez M, Gupta A, Wu C, Silberberg G, Luo J, Markram H (2004) Anatomical, physiological and molecular properties of Martinotti cells in the somatosensory cortex of the juvenile rat. J Physiol 561: 65-90. CrossRef Medline

Warren RA, Agmon A, Jones EG (1994) Oscillatory synaptic interactions between ventroposterior and reticular neurons in mouse thalamus in vitro. J Neurophysiol 72:1993-2003. Medline

Wehr M, Zador AM (2003) Balanced inhibition underlies tuning and sharpens spike timing in auditory cortex. Nature 426:442-446. CrossRef Medline

Weyand TG, Boudreaux M, Guido W (2001) Burst and tonic response modes in thalamic neurons during sleep and wakefulness. J Neurophysiol 85:1107-1118. Medline

Zhan XJ, Cox CL, Rinzel J, Sherman SM (1999) Current clamp and modeling studies of low-threshold calcium spikes in cells of the cat's lateral geniculate nucleus. J Neurophysiol 81:2360-2373. Medline

Zhuang X, Masson J, Gingrich JA, Rayport S, Hen R (2005) Targeted gene expression in dopamine and serotonin neurons of the mouse brain. J Neurosci Methods 143:27-32. CrossRef Medline 